내경계막을 제거하지 않은 황반원공의 수술적 폐쇄 후의 황반 혈관의 이동

\title{
Topographic Changes in the Macula after Closure of Idiopathic Macular Hole without Internal Limiting Membrane Peeling
}

\author{
권한조,2, 박성후 ${ }^{1,2}$, 이지은,2 \\ Hanjo Kwon ${ }^{1,2}$, Sung Who Park ${ }^{1,2}$, Ji Eun Lee ${ }^{1,2}$ \\ ${ }^{1}$ 부산대학교 의과대학 안과학교실, ${ }^{2}$ 부산대학교병원 의생명연구원 \\ 'Department of Ophthalmology, Pusan National University School of Medicine, Yangsan, Korea \\ ${ }^{2}$ Biomedical Research Institute, Pusan National University Hospital, Busan, Korea
}

Purpose: To compare topographic changes in the macula after closure of idiopathic macular hole both with and without internal limiting membrane peeling.

Methods: This study enrolled patients with stage 2 idiopathic macular hole with a diameter less than $300 \mu \mathrm{m}$ who had undergone vitrectomy for macular hole closure from January 2012 to January 2016: four eyes of four patients (group 1) without internal limiting membrane peeling and 16 eyes of 16 patients (group 2) with internal limiting membrane peeling. A custom program was developed to analyze displacement of retinal vessels in the macula. The grid comprised two concentric rings of different sizes, each containing eight sectors, and displacement of retinal vessels in each sector was compared. Mean vector distance and angle of retinal vascular displacement of each zone (medial, lateral, superior, and inferior) was calculated from the combination of each sector and compared between the two groups.

Results: Preoperative mean macular hole diameter in groups 1 and 2 was $218.8 \pm 38.9 \mu \mathrm{m}$, and $218.6 \pm 38.1 \mu \mathrm{m}$, respectively $(p>0.05)$. The average displacement distance of retinal vessels in group 1 was $3.4 \mu \mathrm{m}$ with $38.70 \mathrm{from}$ the posterior pole, while the inner and outer concentric rings barely moved (5.5 $\mu \mathrm{m}$, and $1.4 \mu \mathrm{m}$, respectively). However, the average displacement distance of retinal vessels in group 2 was $45.9 \mu \mathrm{m}$ with $0.9^{\circ}$ from the posterior pole, and the inner $\left(59.0 \mu \mathrm{m}, 2.8^{\circ}\right)$ and outer rings $\left(32.9 \mu \mathrm{m},-2.4^{\circ}\right)$ shifted to the nasal side. Retinal vascular displacement appeared to be significantly lower in the group without internal limiting membrane peeling compared to the group with internal limiting membrane peeling.

Conclusions: Retinal vascular displacement is minimal after vitrectomy without internal limiting membrane peeling in cases of small macular hole, which supports the hypothesis of previous studies that the internal limiting membrane contributes to structural maintenance of the macula and inhibits macular displacement.

Keywords: Internal limiting membrane; Macular hole; Topographic change

\section{Address reprint requests to Ji Eun Lee, MD, PhD}

Department of Ophthalmology, Pusan National University Hospital, \#179 Gudeok-ro, Seo-gu, Busan 49241, Korea Tel: 82-51-240-7957, Fax: 82-51-242-7341

E-mail: jlee@pusan.ac.kr
Received: 2017. 6. 27

Revised: 2017. 10.9

Accepted: 2017. 10. 19

* This work was supported by clinical research grant in 2016 from Pusan National University Hospital. 


\section{서론}

내경계막은 전층 황반원공의 발생과 관련이 있으며, 이를 제거 하면 전층 황반원공의 수술 성공률을 높일 수 있다[1,2]. 내경 계막의 제거가 황반원공의 폐쇄에 기여하는 기전과 정확한 치 유 과정에 대해서는 의견이 분분하나, 유리체절제술과 함께 내 경계막 제거술을 시행하면 원공 전후 방향 및 접선 방향의 견 인력이 제거되어 원공 경계면이 접근하고 중심오목 조직의 신 장이 이루어지면서 원공이 폐쇄되는 것으로 생각되고 있다[3]. Madreperla et al. [4]은 내경계막 제거로 인해 교세포의 증식이 촉진되고 이 과정에서 뮬러세포의 증식이 일어나면서 원공 폐 쇄가 일어나게 된다고 주장하였다. 술 후 황반 이동에서 내경계 막의 제거의 역할에 대해서는 아직 완전히 규명되지 않았다. 본 원의 연구에서 황반원공의 수술에서 내경계막 제거 후 황반이 시신경 유두 방향 및 구심성(centripetal)으로 이동한다는 결과 를 보고하였지만[5], 내경계막을 제거하지 않은 대조군이 없어 관찰된 이동이 유리체절제술 후 황반원공 폐쇄과정에서 일어나 는 일반적인 현상과 구별할 수 없다는 한계가 있었다.

황반원공의 수술 중 내경계막 제거는 술기의 발달로 황반조 직에 심각한 손상 없이 성공률을 높이고 재발을 낮출 수 있어 [6], 최근 수술 경향은 대부분의 황반원공 수술에서 내경계막 의 제거가 이루어지기 때문에 내경계막의 제거 여부가 황반 이 동이나 해부학적 구조에 미치는 영향에 대해서는 아직까지 자 세히 비교한 연구가 없다. 본 연구에서는 2기 전층 황반원공의 수술 후 내경계막을 제거한 경우와 제거하지 않은 경우, 각각 의 망막혈관위치를 비교 분석하여 후극부의 지형학적 변화를 조사하고 내경계막의 제거가 황반 이동에 미치는 영향을 규명 하고자 한다.

\section{대상과 방법}

2012년 1월부터 2016년 6월까지 부산대학교병원 안과를 내원한 환자들 중 제 2 기 특발성 전층 황반원공으로 진단되고 원공 직 경이 $300 \mu \mathrm{m}$ 이하인 환자들을 대상으로 하였다. 환자들 중 망 막앞막 및 $-5.0 \mathrm{D}$ 이상의 고도 근시 혹은 혈관의 이동에 영향을 미치는 다른 망막질환이 있는 경우는 제외하였다. 내경계막을 제거하지 않은 눈을 연구군으로 하고, 원공의 크기를 일치시킨 내경계막을 제거한 눈을 4배수로 선정하여 대조군으로 하여 의 무기록을 후향적으로 분석하였다. 본 연구는 부산대학교병원 기관윤리심의위원회의 심의면제 승인(IRB No. 1706-004-056) 후 진행되었다.

수술방법은 25게이지 평면부 유리체절제술을 시행하여 완전 한 뒤유리체박리를 유도하고 유리체를 제거하였다. 내경계막 제 거술을 시행한 군은 $0.025 \%$ brilliant blue $\mathrm{G}$ (BBG)를 이용하여
내경계막을 염색한 후 원공 주변의 내경계막을 벗겼다. 액체-기 체 치환술 후 술자의 판단에 따라 액체-공기 치환 상태로 수술 을 종료하거나 추가로 공기-가스 치환술까지 시행 후 종료하였 다. 백내장을 동시에 수술하는 경우에는 유리체절제술에 앞서 투명각막절개창을 만들고 수정체유화술로 수정체를 제거한 뒤 인공수정체를 수정체낭에 삽입하였다.

두 군 모두에서 수술 전과 술 후 6개월에 시력검사, 산동 후 안저사진촬영, 빛간섭단층촬영(optical coherence tomography [OCT], DRI OCT-1 Atlantis, Topcon Medical, Oakland, NJ, USA) 검사를 시행하였다. OCT는 $512 \times 256 \mathrm{~A}-\mathrm{scan}$ 프로토 콜로 황반의 $6 \times 6 \mathrm{~mm}$ 영역을 촬영하였다. 이후 256 장의 수 평 A-scan에서 관찰되는 원공의 최소직경을 원공 직경(Hole diameter)으로 하여 조사하였다. 내경계막의 제거 범위 및 유리 체 충전에 사용한 가스의 종류는 수술기록을 참고하였다.

혈관이동의 측정은 이전에 보고된 방법[5]으로 혈관이동을 분 석하기 위해 제작된 프로그램을 이용하여 수술 전후 사진을 비 교하여 이루어졌다(Fig. 1). 간단히 기술하면, 술 후 안저사진의 크기와 각도를 조정하여 술 전 안저사진에 맞추고, $6 \times 6 \mathrm{~mm}$ 정면빛간섭단층촬영 영상을 등록하여 안저사진의 실제 축적을 계산하였다. 8 개 구획(이측, 상이측, 상측, 상비측, 비측, 하비측, 하측, 하이측)으로 나눠진 2개의 동심고리(안 고리 및 바깥 고 리, 안 고리는 중심와로부터 2.0-4.0 mm 범위, 바깥 고리는 중 심와로부터 4.0-6.0 mm 범위)로 구분되어 총 16개의 구획을 가 진 격자를 사진 위에 겹친 뒤, 혈관 분지와 같은 특징점의 위치 를 비교하여 술 전과 술 후 6 개월 사이 혈관이동을 측정하였다. 한 구획 안에 2 개 이상의 특징점이 있는 경우 그 구획의 중심에 서 가장 가까운 특징점을 선택하였다. 수평과 수직 방향의 혈 관이동량을 측정하고 혈관이동 벡터의 크기(amplitude)와 각도 (orientation)를 계산하였다. 크기의 단위는 $\mu \mathrm{m}$, 각도의 단위는 degree로, 양의 방향은 우안을 기준으로 중심와에서 코쪽의 가 상의 수평선을 $0^{\circ}$ 로 지정하고 각도의 양의 증가방향은 시계 반 대방향이라고 정의하였다. 각 구획과 고리의 수평 및 수직 이동 을 평균하여 각 영역(비측, 상측, 이측, 하측)의 혈관이동 벡터 의 평균을 구하였다. 이후 각 영역의 두 군 사이 평균 벡터 크 기를 비교하였다.

비측 영역의 평균 혈관 이동 벡터의 크기는 상비측, 비측 및 하비측 구획의 혈관이동 벡터 합으로 구하였다. 같은 방법으로 상측 영역은 상이측, 상측 및 상비측 구획의 혈관이동 벡터 합 으로, 이측 영역은 상이측, 이측 및 하이측 구획의 혈관이동 벡 터 합으로, 하측 영역은 하비측, 하측 및 하이측 구획의 혈관이 동 벡터 합으로 구하였다. 통계학적 분석은 SPSS ver. 21.0 (IBM Corp., Armonk, NY, USA)을 사용하였으며 두 군 간의 비교에 는 Mann-Whitney $U$ test를 사용하였고 $p$ 값이 0.05 이하일 때 유의하다고 정의하였다. 


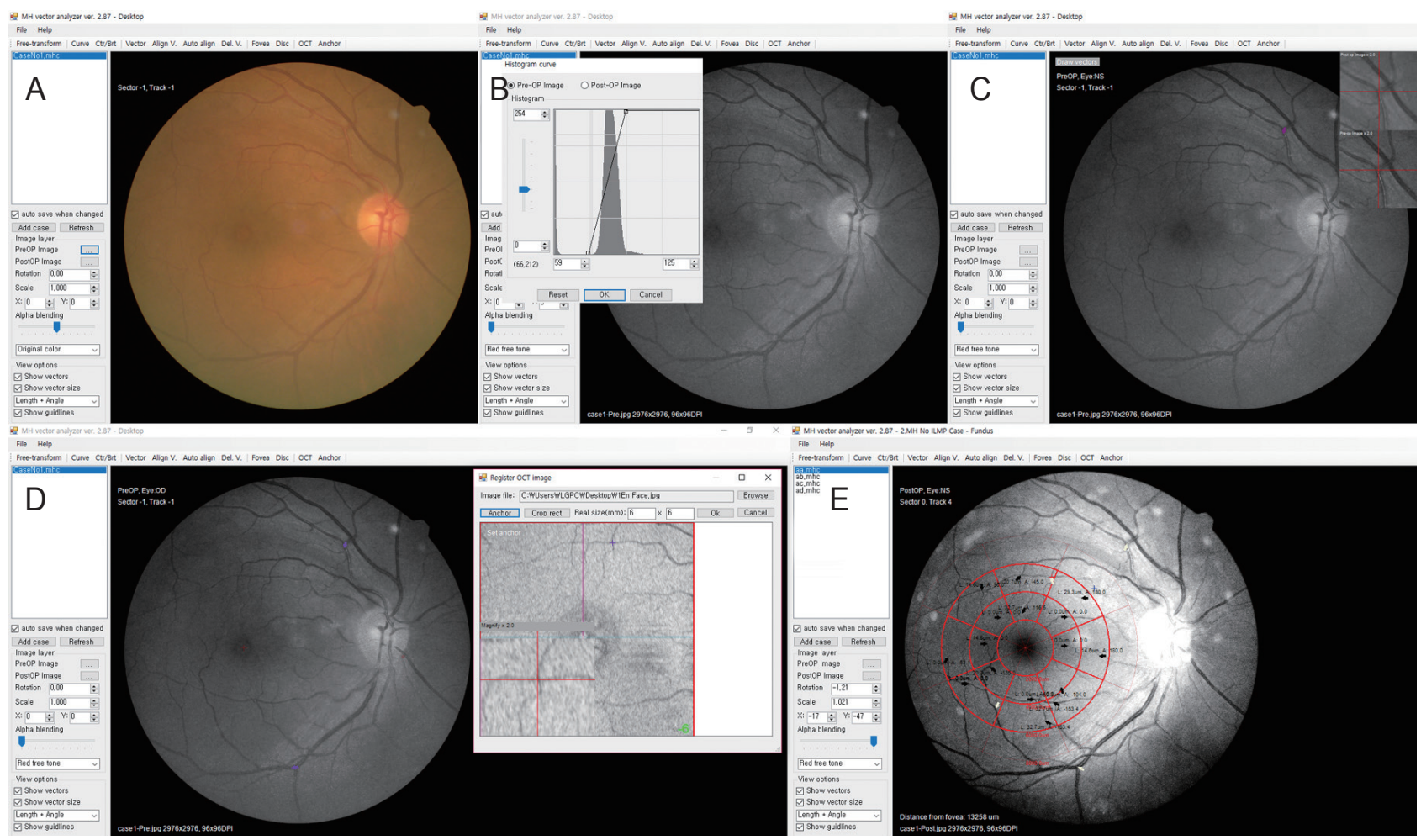

Figure 1. Measurement of preoperative and postoperative vascular shift in macular hole patients using custom software. (A) Pre- and post-operative fundus photographs of macular hole patients (case no. 1) were loaded on the custom software. (B) Visualization of the retinal vessels was enhanced by truncating redundant levels and adjusting brightness/contrast. (C) The scale, angle and position of post-operative photographs were adjusted in order to match the two photographs by registering the 4 points of vascular bifurcation. (D) En face image of a $6 \times 6$-mm optical coherence tomography volume scan registered by matching two vascular bifurcations to calculate the scale of the photograph. (E) A grid of 16 sectors was superimposed over the photographs, and vascular shift was measured in each sector.

Table 1. Baseline characteristics and surgical outcomes

\begin{tabular}{lccc}
\hline Factors & No ILMP group & ILMP group & $p$-value \\
\hline Total eyes & 4 & 16 & 0.148 \\
Mean age (years) & $63.5 \pm 0.6$ & 6.10 & 0.3 \\
Laterality (OD:OS) & $1: 3$ & $0.725 \pm 0.315$ & 0.178 \\
Mean preoperative VA (logMAR) & $0.500 \pm 0.216$ & $0.225 \pm 0.139$ & 0.064 \\
Mean postoperative VA (logMAR) & $0.075 \pm 0.096$ & $218.8 \pm 38.9$ & 0.963 \\
Hole diameter ( $\mu$ m) & $218.6 \pm 38.1$ & $3.1 \pm 0.6$ & $7: 9$ \\
ILMP (DD area) & $0.0 \pm 0.0$ & & \\
Type of gas (air:SF $18.0 \%)$ & $4: 0$ & &
\end{tabular}

Values are presented as mean \pm SD unless otherwise indicated.

ILMP = internal limiting membrane peeling; $\mathrm{OD}=$ oculus dexter; $\mathrm{OS}=$ oculus sinister; $\mathrm{VA}=$ visual acuity; $\mathrm{DD}=$ disc diameter; $\mathrm{SF} 6=$ surfur hexafluoride.

\section{결과}

총 20명 20안이 포함되었고 이 중 4안(20.0\%)은 내경계막을 제거하지 않았다. 평균 나이는 $65.1 \pm 4.8$ 세였고 우안은 7안
(35.0\%), 좌안은 13 안 $(65.0 \%)$ 이었다. 원공의 평균 지름은 218.7 $\pm 37.2 \mu \mathrm{m}$ 였다. 술 전 평균 시력은 $0.68 \pm 0.31$ 이었다.

두 군 간의 나이, 술 전 및 술 후 시력은 차이가 없었다. 술 중 내경계막을 제거하지 않은 군의 원공 직경은 $218.8 \pm 38.9 \mu \mathrm{m}$ 
A

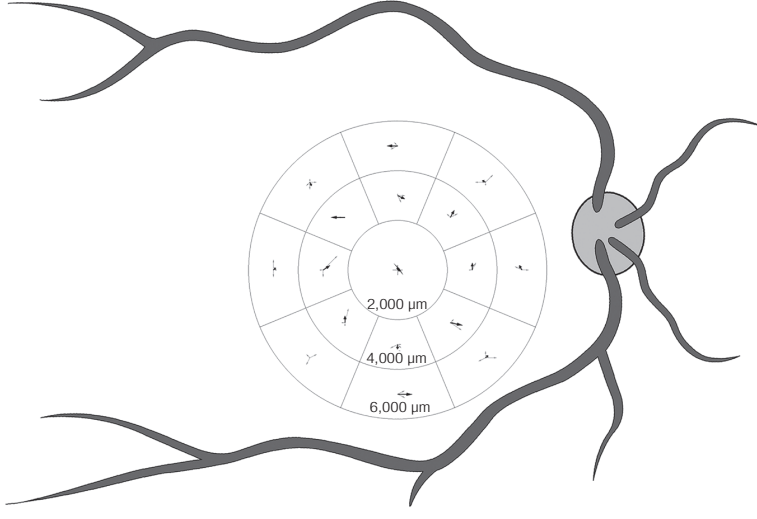

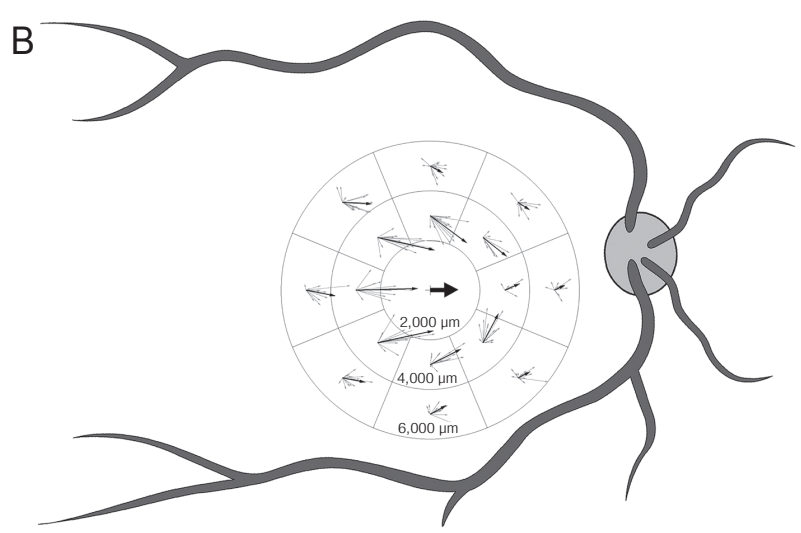

Figure 2. Schematic drawings of the displacement of retinal vessels after surgical macular hole closure in the no-internal limiting membrane peeling (ILMP) group and the ILMP group. Upper schematic drawing (A) shows displacement of the retinal vessels after surgical macular hole closure in the no-ILMP group. Lower schematic drawing (B) shows displacement of retinal vessels after surgical macular hole closure in the ILMP group. Thin arrows represent displacement in each case. Thick arrows represent mean displacement of whole sectors. The length of the arrows is ten-fold that of actual displacement for improved visualization.

Table 2. Vascular displacement after macular hole surgery with or without removal of the internal limiting membrane

\begin{tabular}{|c|c|c|c|c|c|}
\hline \multirow{2}{*}{ Zones } & \multicolumn{2}{|c|}{ No ILMP group } & \multicolumn{2}{|c|}{ ILMP group } & \multirow{2}{*}{$p$-value } \\
\hline & Amplitude ( $\mu \mathrm{m})$ & Orientation (degree) & Amplitude $(\mu \mathrm{m})$ & Orientation (degree) & \\
\hline Whole sectors & 3.4 & 38.7 & 45.9 & 0.9 & $<0.001$ \\
\hline Inner ring & 5.5 & 31.9 & 59.0 & 2.8 & $<0.001$ \\
\hline Outer ring & 1.4 & 66.4 & 32.9 & -2.4 & 0.006 \\
\hline Nasal & 6.2 & 63.8 & 22.4 & 18.1 & 0.040 \\
\hline Temporal & 2.9 & 51.4 & 72.6 & -2.4 & $<0.001$ \\
\hline Superior & 1.1 & -163.2 & 52.1 & -22.3 & $<0.001$ \\
\hline Inferior & 6.3 & 3.8 & 52.1 & 23.7 & $<0.001$ \\
\hline Inner nasal & 9.9 & 38.5 & 25.2 & 27.9 & 0.061 \\
\hline Inner temporal & 6.1 & 79.3 & 95.2 & 0.5 & $<0.001$ \\
\hline Inner superior & 2.8 & 13.5 & 69.6 & -25.3 & 0.001 \\
\hline Inner inferior & 6.2 & -2.0 & 73.2 & 28.6 & $<0.001$ \\
\hline Outer nasal & 5.5 & 114.1 & 20.4 & 5.9 & 0.106 \\
\hline Outer temporal & 2.9 & -31.8 & 50.4 & -8.0 & 0.050 \\
\hline Outer superior & 4.9 & -165.1 & 34.9 & -16.3 & 0.006 \\
\hline Outer inferior & 6.5 & 9.3 & 31.9 & 12.3 & 0.192 \\
\hline
\end{tabular}

ILMP = internal limiting membrane peeling.

*Comparing amplitude between two groups with Mann-Whitney U test.

로 제거한 군의 원공 직경 $218.6 \pm 38.1 \mu \mathrm{m}$ 와 차이가 없었다 (Table 1). 내경계막을 제거하지 않은 군은 모두 공기로 유리체 강을 충전하였고, 내경계막을 제거한 군에서는 9안(56.2\%)에서 $18.0 \% \mathrm{SF}_{6}$ 가 사용되었으며 나머지는 공기가 사용되었다. 내경계 막을 제거한 군의 내경계막 제거범위는 $3.1 \pm 0.6 \mathrm{DD}(2.0-4.0$ $\mathrm{DD})$ 였다. 두 군의 20안 모두 한 번의 수술로 원공이 폐쇄되었으
며 그 외 수술 관련 합병증은 없었다.

내경계막을 제거하지 않은 군에서 황반원공 환자의 후극부의 평균 혈관이동은 $3.4 \mu \mathrm{m}\left(38.7^{\circ}\right)$ 였다(Fig. $2 \mathrm{~A}$, Table 2). 안쪽 고 리뿐만 아니라 바깥 고리에서의 이동도 각각 $5.5 \mu \mathrm{m}$ 및 $1.4 \mu \mathrm{m}$ 로 매우 작았다. 각 영역의 이동은 하측 $(6.3 \mu \mathrm{m})$, 비측 $(6.2 \mu \mathrm{m})$, 이측 $(2.9 \mu \mathrm{m})$, 상측 $(1.1 \mu \mathrm{m})$ 순으로 조사되었고 뚜렷한 방향성 
Table 3. Vascular displacement after macular hole surgery and removal of the internal limiting membrane between air and SF 6 18.0\% tamponade group

\begin{tabular}{|c|c|c|c|c|c|}
\hline \multirow{2}{*}{ Zones } & \multicolumn{2}{|c|}{ ILMP group (air tamponade) } & \multicolumn{2}{|c|}{ ILMP group (SF6 18.0\% tamponade) } & \multirow{2}{*}{$p$-value ${ }^{*}$} \\
\hline & Amplitude $(\mu \mathrm{m})$ & Orientation (degree) & Amplitude ( $\mu \mathrm{m})$ & Orientation (degree) & \\
\hline Whole sectors & 46.3 & 2.7 & 45.6 & -0.5 & 1.000 \\
\hline Inner ring & 58.5 & 4.0 & 59.5 & 1.8 & 1.000 \\
\hline Outer ring & 34.3 & 0.4 & 31.8 & -4.8 & 0.758 \\
\hline Nasal & 27.3 & 27.5 & 19.2 & 7.6 & 0.918 \\
\hline Temporal & 65.9 & -1.4 & 77.9 & -3.1 & 0.758 \\
\hline Superior & 53.6 & -22.0 & 50.9 & -22.5 & 0.918 \\
\hline Inferior & 59.3 & 24.5 & 46.5 & 22.8 & 0.351 \\
\hline Inner nasal & 29.5 & 40.5 & 23.0 & 15.5 & 0.758 \\
\hline Inner temporal & 84.9 & 1.6 & 103.3 & -0.2 & 0.606 \\
\hline Inner superior & 72.2 & -25.1 & 67.6 & -25.5 & 0.758 \\
\hline Inner inferior & 82.2 & 29.3 & 66.1 & 27.9 & 0.536 \\
\hline Outer nasal & 26.7 & 13.2 & 15.9 & -3.7 & 0.351 \\
\hline Outer temporal & 47.2 & -6.7 & 52.9 & -8.3 & 0.758 \\
\hline Outer superior & 35.3 & -15.9 & 34.6 & -16.6 & 0.918 \\
\hline Outer inferior & 37.3 & 14.0 & 27.7 & 10.6 & 0.681 \\
\hline
\end{tabular}

ILMP = internal limiting membrane peeling.

${ }^{*}$ Comparing amplitude between two groups with Mann-Whitney $U$ test.

은 관찰되지 않았다. 이에 비하여 내경계막을 제거한 군의 평균 혈관이동은 이전 보고와 마찬가지로 시신경유두 방향에 해당하 는 비측 및 중심와로 향하는 구심성으로 나타났으며, 각 영역은 내경계막을 제거하지 않은 군의 구획에 비해 혈관이동이 유의하 게 컸다(Fig. 2B, Table 2). 내경계막을 제거한 16안의 전체 구획 의 평균은 $0.9^{\circ}$ 각도로 $45.9 \mu \mathrm{m}$ 였고 $(p<0.001)$, 안 고리에서는 $59.0 \mu \mathrm{m}(p<0.001)$, 바깥 고리에서는 $32.9 \mu \mathrm{m}(p=0.006)$ 로 모 두 비측(안 고리 $2.8^{\circ}$, 바깥 고리 $-2.4^{\circ}$ )으로 이동하였다. 각 영 역 이동은 이측 $(72.6 \mu \mathrm{m}, p<0.001)$ 이 가장 컸고, 비측 $(22.4 \mu \mathrm{m}$, $p=0.040)$ 이 가장 작았다. 상측 및 하측은 그 중간 크기였다(각 각 $52.1 \mu \mathrm{m}, p<0.001$ 및 $52.1 \mu \mathrm{m}, p<0.001)$.

내경계막을 제거한 군에서 술 후 충전물로 공기를 사용한 군 과 $\mathrm{SF}_{6} 18 \%$ 비팽창가스를 사용한 군의 후극부의 평균 혈관이 동을 비교하기 위한 소집단 분석(subgroup analysis)을 실시하였 다(Table 3). 두 군 간 어떠한 조사 영역도 통계적으로 유의한 차 이는 관찰되지 않았고, 후극부의 혈관 이동 경향은 비슷하였다.

\section{고찰}

내경계막은 망막과 유리체 사이의 해부학적 경계로 견인력을 유 발하고 세포 증식의 골격으로 작용하여 황반원공의 발생과 관
련된다[1]. 황반원공의 치료는 내경계막제거술이 소개된 이후 수술 성공률은 약 80-90\%에 이를 정도로 우수하다[7,8]. 원공 이 폐쇄되는 기전은 아직 명확히 알려지지는 않았으나, 수술을 통해 전후 방향 및 접선 방향의 견인력을 제거하면 원공경계면 이 서로 접근하고, 교세포 및 기타 다른 세포들의 증식이 자극 되어 신경망막의 결손된 부분을 메우는 것으로 생각된다. 눈속 충전물은 원공으로의 액체 유입을 막고 망막 내층으로 충전된 가스의 경계면에서 교세포 조직의 이주를 촉진하고 증식하여 원공의 폐쇄를 유도하는 역할을 한다. 내경계막의 제거는 접선 방향의 견인을 제거할 뿐 아니라 원공의 완전 폐쇄에 필수적인 교세포의 증식도 촉진하는 것으로 보고 있다[9,10].

이번 연구에서 내경계막을 제거한 군에서 황반원공의 수술 적 폐쇄 후의 혈관은 시신경 유두 쪽의 일관된 방향으로 이동 하였다. 이는 앞서 보고된 다른 연구들과 일치하는 결과이다 [5,11,12]. 이에 비하여 내경계막을 제거하지 않은 군에서 평균 혈관이동은 $3.4 \mu \mathrm{m}$ 로 내경계막을 제거한 군의 $45.9 \mu \mathrm{m}$ 보다 매 우 작았다 $(p<0.001)$. 이전 연구에서 술 후 평균 황반이동은 원 공지름과 내경계막 제거범위와 관련이 있었는데[5], 이번 연구 에서 원공 크기가 작고 내경계막을 제거하지 않은 4안의 전층 황반원공에서 술 후 황반 이동이 매우 작음은 내경계막이 황 반 이동을 억제하는 지지구조 역할을 한다는 이전 연구의 주 장을 뒷받침한다. 
내경계막의 제거 후 황반이동이 발생하는 기전을 제시한 몇몇 연구들이 있는데, 제거하지 않고 남은 내경계막의 수축이 원인 일 것이라는 주장[13]과 망막신경섬유층 수축에 의할 것으로 추 정하는 연구[14]가 있다. 이번에 조사한 내경계막을 제거하지 않 은 눈들의 경우 이동 크기가 매우 작았고 이동방향의 경향성은 나타나지 않았다. 내경계막을 제거한 눈들은 시신경유두방향에 해당하는 비상측으로 이동하였다. 이는 내경계막이 제거된 부 위는 내경계막이 제거되어 망막신경조직을 고정하는 조직이 없 어져서 망막신경섬유층 수축으로 인해 신경망막의 이동이 가능 해진다는 후자의 주장을 뒷받침한다. 한편으로 내경계막을 제 거하지 않은 군에서 관찰되는 불규칙한 소량의 이동은 내경계 막 표면에서 증식한 교세포들의 수축이 망막이동을 유발한다 는 전자의 주장과 연관성이 있다. 교세포들의 양이 적고 분포가 불규칙하다면 본 연구에서 관찰된 소견을 설명할 수 있을 것이 다. 다만 내경계막이 제거된 부위, 특히 잔존하는 내경계막에서 거리가 먼 중심오목 부위에 잔존한 내경계막, 혹은 표면의 교세 포의 수축이 미치는 영향은 적을 것으로 생각된다.

이전의 본원 주관 다기관 연구에서는 내경계막 제거 후 황반 혈관은 비측방향 외에도 구심성 이동이 관찰되었는데[5], 그 이 유는 내경계막제거 후 황반은 좀 더 유연해지고 원공이 닫히는 과정에서 구심성으로 이동한다고 설명하였다. 내경계막을 제거 하지 않은 4 안에서는 구심성의 이동도 관찰되지 않았으며, 크 기가 작은 원공의 폐쇄에서는 망막 내층으로 충전된 가스의 경 계면에서 교세포 조직의 이주와 증식만으로 망막조직의 구심성 이동 없이 원공이 폐쇄되었음을 의미한다. 이는 크기가 큰 원공 에서는 내경계막 제거 없이 가스의 충전만으로 원공폐쇄의 성 공률이 낮아지는 것을 반증한다.

본 연구에서 4 안의 환자들은 $250 \mu \mathrm{m}$ 부근의 작은 전층황반 원공의 환자들로 내경계막을 제거하지 않아도 술 후 우수한 시 력과 원공폐쇄를 확인할 수 있었는데, 추가 연구를 통하여 제2 기 전층 황반원공 환자들을 대상으로 내경계막 제거술이 꼭 필 요한 황반원공의 크기에 대해 조사할 필요가 있다. 황반원공의 수술에서 내경계막을 제거하면 높은 해부학적 성공률을 얻을 수 있는데 비해 기능적 성공률은 그에 미치지 못한 경우가 많 은데 이는 내경계막제거 시 뮬러세포의 손상 및 신경섬유층의 기계적인 손상을 받게 되고, 황반구조에 영향을 미쳐 시력회복 에 불리한 요소로 작용하기 때문이다[2]. 황반의 제거된 내경계 막을 면역화학염색 후 뉴런세포와 신경절세포를 발견했다는 것 이 이를 뒷받침하며[15], Kim et al. [16]은 내경계막제거술 시 내 경계막을 잡아당기는 힘으로 인해 일시적인 허혈상태가 야기될 수 있고, 허혈성 변화에 민감한 신경절세포의 손상으로 신경절 세포-내망상층의 두께가 감소될 수 있다는 가설을 제시하였다. 따라서 내경계막을 제거하지 않는 술식은 술 후 황반의 해부학 적 변형을 예방할 수 있다는 장점이 있을 것이다.

최근 오크리플라스민(Jetrea, ThromboGenics, New Jersey,
NJ, USA)을 사용한 유리체용해술에 관한 연구에서 단 한 번의 주입으로도 $40 \%$ 에 해당하는 전층 황반원공의 환자들의 원공 이 폐쇄되어 모든 전층 황반원공에서 유리체절제술이나 내경계 막 제거가 필요하지는 않다는 것을 보였다[17]. 제2기 전층 황반 원공 중에서도 크기가 작은 원공에 대해서 선택적으로 내경계 막을 제거하지 않고 유리체절제술만 시도하는 보존적인 방법을 주장하는 술자도 있다.

본 연구는 후향적 연구로 대상 환자의 수가 작은 한계점이 있 고, 짧은 경과 관찰기간은 해부학적 변화와 재발을 보기에 충분 하지 않다. 또한 두 군 간의 기능적 변화를 비교한 연구는 아니 다. 전층 황반원공에서 내경계막을 제거하지 않은데 대한 수술 실패 및 재발의 우려가 있어, 특발성 2기 전층 황반원공 중 원 공직경이 $300 \mu \mathrm{m}$ 이하인 환자들을 대상으로 하였기 때문에 본 연구 결과를 모든 특발성 2기 전층 황반원공 환자에 적용하기 에는 한계가 있다. 내경계막의 제거 범위를 수술 동영상이 아닌 술자의 기록만으로 조사하여 제거된 내경계막의 경계가 대칭적 인지 조사하지 못한 점은 본 연구의 한계점이다. 또한 내경계막 제거술을 시행한 군 일부에서 공기가 아닌 $\mathrm{SF}_{6}$ 가 충전물로 사 용되어 두 군 간의 충전물 분포가 일치되지 않은 점은 본 연구 의 한계로 사료된다. 하지만 6 개월의 경과 관찰기간은 황반원공 수술 후 1 차 원공폐쇄를 평가하기에 충분한 기간이며 두 군 간 의 선택편향(selection bias)을 최소화하기 위해 조사 전 원공의 크기와 나이 등, 술 전 인자들을 가급적 일치시켰고 한 명의 술 자에 의해 수술이 시행된 환자들만을 대상으로 하였다. 또한 소 규모 분석을 통하여 술 중 공기를 충전한 경우와 $\mathrm{SF}_{6} 18 \%$ 비팽 창가스를 충전한 경우를 비교하여 두 군 간의 후극부 혈관이동 에는 차이가 없음을 제시하였다.

결론적으로 내경계막은 황반 이동을 억제하는 지지구조 역할 을 하며, 내경계막을 제거하지 않으면 황반이동이 억제되어 원 공의 크기가 큰 제 3 기 및 4 기 전층 황반원공의 수술에서 해부학 적 성공에 불리하게 작용할 것으로 사료된다. 전층 황반원공에 서 내경계막을 보존하는 경우의 기능적 성적과 수술 성공률의 저하 없이 내경계막을 보존할 수 있는 조건에 대한 추가 연구가 필요할 것으로 사료된다.

\section{Conflicts of interest}

The authors have no conflicts to disclose.

\section{References}

1. Guyer DR, Green WR, de Bustros S, Fine SL. Histopathologic features of idiopathic macular holes and cysts. Ophthalmology 1990;97:1045-51.

2. Kwok AK, Lai TY, Man-Chan W, Woo DC. Indocyanine green as- 
sisted retinal internal limiting membrane removal in stage 3 or 4 macular hole surgery. Br J Ophthalmol 2003;87:71-4.

3. Jeong SH, Kim JH, Kim JW, et al. Long-term changes in foveal microstructure after macular hole surgery. J Korean Ophthalmol Soc 2013;54:1731-6.

4. Madreperla SA, Geiger GL, Funata M, et al. Clinicopathologic correlation of a macular hole treated by cortical vitreous peeling and gas tamponade. Ophthalmology 1994;101:682-6.

5. Pak KY, Park KH, Kim KH, et al. Topographic changes of the macula after closure of idiopathic macular hole. Retina 2017;37:66772.

6. Lois N, Burr J, Norrie J, et al. Internal limiting membrane peeling versus no peeling for idiopathic full-thickness macular hole: a pragmatic randomized controlled trial. Invest Ophthalmol Vis Sci 2011;52:1586-92.

7. Tognetto D, Grandin R, Sanguinetti G, et al. Internal limiting membrane removal during macular hole surgery: results of a multicenter retrospective study. Ophthalmology 2006;113:1401-10.

8. Haritoglou C, Reiniger IW, Schaumberger M, et al. Five-year follow-up of macular hole surgery with peeling of the internal limiting membrane: update of a prospective study. Retina 2006;26:618-22.

9. Wender J, lida T, Del Priore LV. Morphologic analysis of stage 3 and stage 4 macular holes: implications for treatment. Am J Ophthalmol 2005;139:1-10.

10. Costa RA, Cardillo JA, Morales PH, et al. Optical coherence to- mography evaluation of idiopathic macular hole treatment by gas-assisted posterior vitreous detachment. Am J Ophthalmol 2001;132:264-6.

11. Smiddy WE, Feuer W, Cordahi G. Internal limiting membrane peeling in macular hole surgery. Ophthalmology 2001;108:14716; discussion 1477-8.

12. Yoshikawa M, Murakami T, Nishijima K, et al. Macular migration toward the optic disc after inner limiting membrane peeling for diabetic macular edema. Invest Ophthalmol Vis Sci 2013;54:62935.

13. Bae K, Kang SW, Kim JH, et al. Extent of internal limiting membrane peeling and its impact on macular hole surgery outcomes: a randomized trial. Am J Ophthalmol 2016;169:179-88.

14. Ishida M, Ichikawa $Y$, Higashida R, et al. Retinal displacement toward optic disc after internal limiting membrane peeling for idiopathic macular hole. Am J Ophthalmol 2014;157:971-7.

15. La Heij EC, Dieudonné SC, Mooy CM, et al. Immunohistochemical analysis of the internal limiting membrane peeled with infracyanine green. Am J Ophthalmol 2005;140:1123-5.

16. Kim KY, Yu SY, Kim MS, et al. Changes of parafoveal retinal nerve fiber layer thickness analyzed by spectral-domain optical coherence tomography after pars plana vitrectomy. Retina 2013;33:776-84.

17. Stalmans P, Benz MS, Gandorfer A, et al. Enzymatic vitreolysis with ocriplasmin for vitreomacular traction and macular holes. N Engl J Med 2012;367:606-15. 


\section{국문초록}

\section{내경계막을 제거하지 않은 황반원공의 수술적 폐쇄 후의 황반 혈관의 이동}

목적: 내경계막을 제거하지 않은 황반원공 및 내경계막을 제거한 황반원공 폐쇄 후 망막혈관의 위치를 분석하여 후극부의 지형학적 변 화의 차이를 조사하였다.

대상과 방법: 특발성 2기 전층 황반원공 중 원공직경이 $300 \mu \mathrm{m}$ 이하인 환자들로 유리체절제술을 하였지만 내경계막 제거술을 시행하 지 않고 황반원공이 폐쇄된 환자 4명 4안(1군)과 내경계막을 제거하고 황반원공이 폐쇄된 16명 16안(2군)을 대상으로 하였다. 혈관이 동을 분석하기 위해 제작된 프로그램을 이용하였다. 8 개 구획으로 나눠진 2 개의 동심고리로 이루어진 격자로 각 구획을 조사하였고, 각 구획 중심에서 가장 가까운 혈관분지의 위치 차이를 측정하였다. 각 구획의 조합으로 이루어진 영역(내측, 이측, 상측, 하측)에서 혈관 이동 벡터의 평균 크기와 각도를 계산하고 두 군 간에 비교하였다.

결과: 수술 전 1군의 원공 직경은 $218.8 \pm 38.9 \mu \mathrm{m}, 2$ 군의 원공 직경은 $218.6 \pm 38.1 \mu \mathrm{m}$ 로 두 군 간의 차이는 없었다. 1 군의 평 균 혈관이동은 후극부에서 $38.7^{\circ}$ 각도로 $3.4 \mu \mathrm{m}$ 였다. 안쪽 원뿐만 아니라 바깥 원의 이동도 거의 없었다 (각각 $\left.5.5 \mu \mathrm{m}, 1.4 \mu \mathrm{m}\right)$. 반 면 2군의 평균 혈관이동은 후극부에서 $0.9^{\circ}$ 각도로 $45.9 \mu \mathrm{m}$ 였고 안쪽 원 $\left(59.0 \mu \mathrm{m}, 2.8^{\circ}\right)$ 및 바깥 원(32.9 $\left.\mu \mathrm{m},-2.4^{\circ}\right)$ 도 비측으 로 이동하였다. 1 군의 술 후 혈관이동은 내경계막을 제거한 군에 비해 모든 영역에서 거의 이동이 없었다.

결론: 작은 황반원공에서 내경계막을 제거하지 않는 경우 혈관 이동은 매우 작으며, 내경계막이 황반 이동을 억제하는 지지구조 역할을 한다는 이전 연구 결과에서 제시한 주장을 뒷받침한다. 